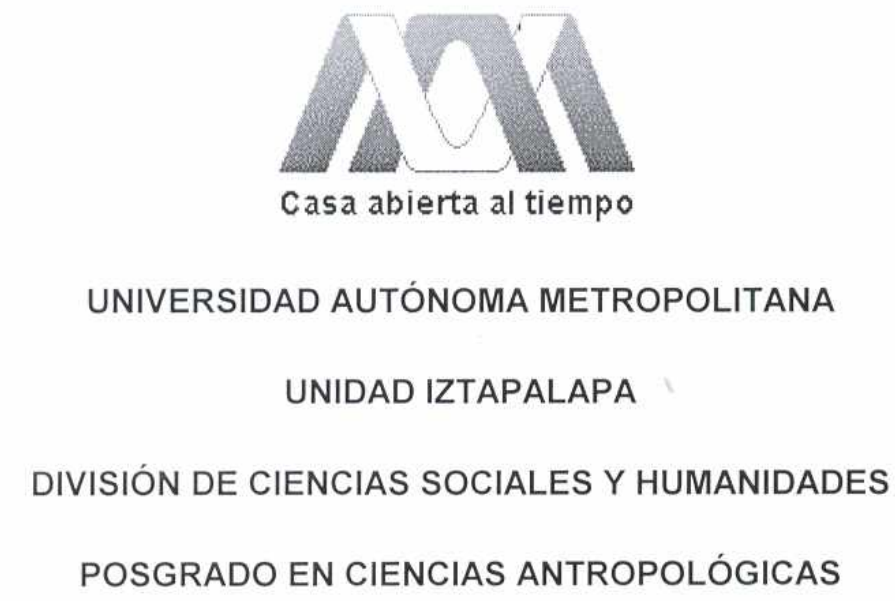

Ciudadanía transnacional: teoría, definiciones y estudio empírico

José Uriel Melchor Moreno

ENSAYO

Para obtener el Diploma de Especialización

en Antropologia Política

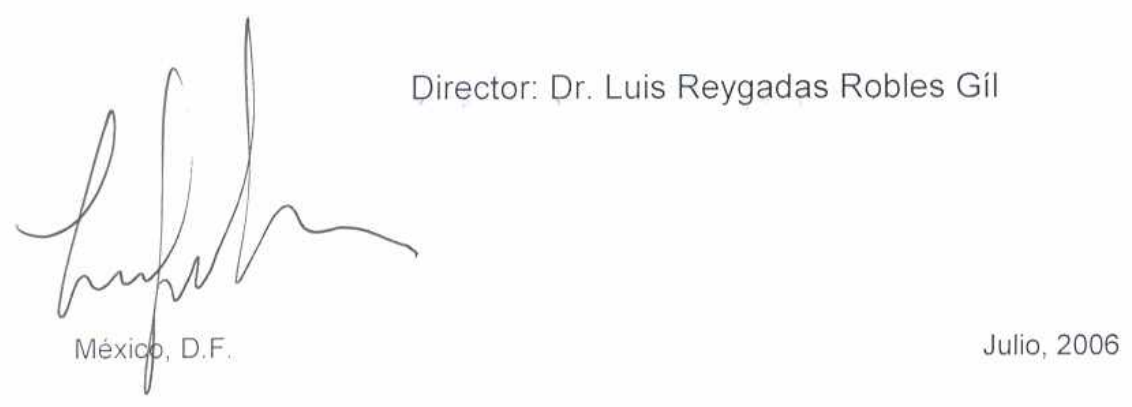




\section{Ciudadanía transnacional: teoría, definiciones y estudio empírico.}

\section{Objetivo.}

El objetivo del presente trabajo es enmarcar el debate de la ciudadanía, avanzar en la propuesta de un concepto de ciudadanía (transnacional) aplicable a las particularidades de la situación de los migrantes (primeramente mexicanos, pero en espera de poder aplicar dicho concepto a otros tipos y cualidades de migrantes); también se establecen los principios de la investigación empírica.

Los limites de este ensayo son los siguientes. Primero, es un primer esbozo que, además de comenzar a situar el contorno de la investigación, marca la línea en que se deberá dirigir el proyecto; se enuncian las rutas que la reflexión deberá seguir. Por lo tanto, se sobreentiende que las reflexiones aquí planteadas no sean definitivas, más bien, están en constante replanteamiento, aunque con algunas de las mismas haya ya un alto nivel de concordancia. Segundo, en torno a la reflexión del concepto de ciudadanía, hay una mayor atención del tema en relación a cómo entenderlo desde la sociedad de destino. ${ }^{1}$ Esto se explica tanto por un supuesto práctico como uno teórico. El supuesto práctico responde a la necesidad de plantear la situación en el primer lugar en que se realizaría la investigación empírica, a saber, la ciudad de Nueva York. En cuanto al supuesto teórico, la recurrencia a explicar la ciudadanía desde el lugar de destino se basa en que el concepto que emerja de esta discusión deberá ser aplicable en ambas situaciones.

En la explicación de la investigación empírica son mayores las dudas y la realización dependerá de la resolución de eventualidades prácticas.

\footnotetext{
* Li Po (poeta): Renmin riba, octubre 22, 1991, en Ong, Aihwa: Flexible Citizenship... pp. 45

1 Esto no excluye la importancia del asunto de la sociedad de origen. Ver más abajo.
} 


\section{Introducción.}

El concepto de ciudadanía surge con las discusiones en torno al Estado-Nación francés, las cuales son herencia del iluminismo. La idea de ciudadanía en ese momento está íntimamente relacionada con la definición asociada a la nación: un territorio, una cultura, un estado. Sobra decir que lo que se encuentra detrás es el proyecto de crear una identidad nacional homogénea dentro de un espacio, de un lugar determinado, al que se pertenecía en relación al otro. ${ }^{2}$

Las condiciones actuales, es decir lo que Jameson (1995) y Harvey (1999), entre otros, consideran la compresión espacio-temporal, implican la reconsideración del concepto de ciudadanía, dado que en términos tradicionales no permite hacer un análisis completo. Lo anterior sólo si suponemos que dicho concepto en algún momento pudo responder a las condiciones en las que se empleó, esta suposición también es cuestionada en este trabajo.

Dado lo anterior, este ensayo está divido en cinco partes principales; en la primera se rastrea el concepto de ciudadanía hasta el iluminismo y se caracteriza en general cuál es la definición tradicional del mismo. En la segunda parte se retoma la reflexión de la así llamada teoría transnacional. En la tercer parte se plantean algunos debates en relación a la ciudadanía transnacional. La parte final se desarrolló tanto para ejemplificar la puesta en práctica de este concepto como para avanzar en la planeación de la investigación.

\section{Parte l: Ciudadanía y los pecados del iluminismo.}

"Algún día todo irá mejor, es nuestra esperanza", ${ }^{3}$ con este enunciado se puede resumir la filosofía del iluminismo.

El iluminismo conjuga tanto el sueño utópico del romanticismo como la racionalidad de la revolución científica. Por un lado, la razón (al menos siguiendo a Mill) "rige no sólo la actividad científica y técnica, sino también el gobierno de los hombres y

2 Cf. Gellner. 1989.

3 Reale, 1995: 565. 
la administración de las cosas". ${ }^{4}$ Entonces, el hombre no se encuentra ya determinado por la voluntad divina, sino que su futuro se abre al azar. Este es el punto fundamental en el que se basa la modernidad, el pensamiento se libera de las nociones básicas de lo concreto y se abre al pensamiento abstracto. Se abre a la posibilidad de la construcción de una realidad. El hombre deja de ser un pupilo y se vuelve un hombre mayor, deja de lado el pensamiento mítico y es el creador de su propia historia: las utopías son posibles.

La modernidad, que se asienta en el iluminismo, refleja una actitud activa del hombre, es una potencia basada en la razón (compartida de los sabios). En esta actitud todo debe ser pesado por el conocimiento científico, por la razón.

Lo anterior tiene como consecuencia que se reflexione en torno a las capacidades, derechos y obligaciones del hombre. La pregunta es ¿Cómo hacer que el hombre se desarrolle y... sea feliz?. En la Francia del siglo XVIII esta reflexión está claramente en contra de las monarquías, ya que son un sistema que reprime y explota a los hombres. La realización más grande de este pensamiento serán los derechos humanos con los que todo hombre debe estar dotado. Sin embargo, el principal problema es la aplicación de esta reflexión abstracta, esto es ¿Cómo concretar los derechos?. La respuesta es el Estado-Nación, éste tendría como obligación principal la de aplicar los mecanismos necesarios para promover y promulgar los mismos.

Surge entonces un problema. La sociedad no es homogénea ni está totalmente estructurada ni unificada. De esta manera, no hay cabida para las diferencias inherentes a cada grupo social. Es necesario compaginar las diferencias por medio de un contrato social que sostenga al Estado y sus decisiones. El principal obstáculo es la sociedad tradicional ${ }^{5}$ ya que lo necesario para la producción es la homogeneidad cultural.

${ }^{4}$ Mill, 1840: 18.

${ }^{5}$ No hay que olvidar que hay una confianza desorbitada en la industrialización y mecanización, como procesos que traerán equidad y bienestar a la sociedad en su conjunto. 
La manera de solucionar esto es por medio de la cultura nacional. Los EstadosNacionales se diferencían hacia dentro, se crea la categoría de lo étnico (es todo lo que está fuera de la sociedad), el otro dentro de nosotros, el tolerado; la reliquia.

\section{El estado y el lluminismo}

El proceso de formación de la nación pasa primero por

La formación de una comunidad política emerge con la idea de soberanía del pueblo y de los individuos, de la lucha contra los privilegios y del resentimiento de las categorías sociales excluidas del ámbito político. ${ }^{6}$

Esta nación se forma, según Gellner (1989), por medio de dos medidas importantes: tanto la amnesia como la educación. En relación a la amnesia, significa el olvido de historias particulares de grupo en miras de ser parte del conjunto mayoritario; elementos tales como la lengua. Esta amnesia es administrada por medio de las escuelas, o como dice Gellner:

es importante no sólo que cada ciudadano aprenda en su escuela primaria el idioma cultivado, sino también que se olvide (o por lo menos devalúe) del dialecto que no es enseñado en la escuela. Tanto el recuerdo como el olvido tienen profundas raíces sociales; ninguno de ellos surge del accidente histórico. (1989: 28)

La educación se encuentra en la base de la construcción del nacionalismo, pero también el uso legítimo de la violencia. Con estas herramientas el estado es capaz de imponer la diferenciación que la industria necesita; capaz de absorber los costos de estos movimiento: de homogeneizar.

\section{La ciudadanía del iluminismo}

La ciudadanía que se construye dentro el contexto del iluminismo es una que sólo obliga a la razón y, por tanto, la convergencia: lo único necesario es la aceptación de la ley, sin importar que la cultura o la lengua sean diferentes. Detrás de esto se encuentra la necesidad de la homogeneización, la asimilación.

6 Elbaz, 1996: 74. 
También puede decirse de la ciudadanía del iluminismo que "denota el carácter de miembro individual de una comunidad política y que conforma uno de los referentes simbólicos básicos de la identidad individual y colectiva de esa comunidad."7 Esto es que está asociada indisolublemente a una serie de derechos y deberes individuales. Este elemento de pertenencia a un grupo cultural específico es un punto que desde ese momento, pero particularmente ahora, representa uno de los principales cuestionamientos a la idea de ciudadanía.

\section{Crisis del estado iluminista}

Existe un problema de origen en torno al concepto de Estado-Nación y esta es su insistencia en la homogeneización. Podemos darnos cuenta de que desde la formación del gran estado francés (el ejemplo que suele citarse al referirse al más importante estado-nación), hubo grupos o minorías que no fueron plenamente integradas, que convivieron pero que acentuaron su diferencia y, de cierta manera, por ello lograron sobrevivir. Como ejemplo de lo anterior se encuentra la situación de los vascos y los catalanes. Por otro lado, de las democracias más recientes y los estados nación actualmente más grandes y fuertes, se encuentran los Estados Unidos que hacia adentro contiene grandes grupos con, incluso, deseos secesionistas (por ejemplo Hawai).

El Estado-Nación del siglo XIX es cuestionado desde dentro, también viene perdiendo importancia, algunos autores sostienen que "El estado es pensable, en realidad, solamente por su geopolítica". ${ }^{8}$ Esto significa que no es ya el gran autor de las grandes transformaciones, no forma ya a sus ciudadanos. ${ }^{9}$

La crisis del estado de bienestar se manifiesta en su incapacidad para reemplazar a las instancias privadas productoras de solidaridad nacional y para

\footnotetext{
7 Requejo, 1996: 99.

8 Elbaz, 1996: 77

9 Esto porque en muchos lugares la educación ha sido privatizada además de que muchos programas educativos son acusados por estar enfocados a satisfacer las necesidades de las corporaciones privadas (con escasa o nula identificación nacional). La identidad nacional, si alguna vez hubo algo así, se está diluyendo.
} 
responder a las desilusiones de los ciudadanos frente a los proyectos modernistas y al debilitamiento del espacio de la nación. ${ }^{10}$ En cuanto a la ciudadanía se puede decir que también se encuentra en debate incluso por las acciones de discriminación positiva hacia minorías tradicionalmente excluidas. Esto rompe con la homogeneidad buscada, ya que se reconoce la diferencia dentro del estado mismo. Esto no significa que esté condenado a la desaparición, sino a la transformación.

\section{Parte II: Migración, redes, asimilación, transnacionalidad.}

La teoría clásica de la migración ha considerado que los migrantes llegados a una nueva sociedad suelen asimilar los contenidos culturales con el afán de volverse como dicha sociedad. La suposición que se puede encontrar detrás va desde los supuestos de la 'elección racional' hasta temores racistas o étnicos y llega hasta la creación e impulso de políticas públicas con ese fin.

En el caso de los migrantes mexicanos, no hay una asimilación ni aceptación de valores prevalecientes en la sociedad norteamericana, en muchas ocasiones las generaciones se suceden una a otra y permanecen los rasgos distintivos de sus lugares de origen. Esto en ocasiones implica el que se mantengan bajos niveles de vida que, al menos hasta ahora ${ }^{11}$ han sido subsanados por un comportamiento particular que ha dado pie a una interpretación teórica denominada teoría transnacional. Por ello a continuación presento algunas generalidades de la teoría transnacional.

\section{La teoría transnacional.}

La teoría transnacional es, relativamente, nueva. Fue el equipo de Basch, GlickSchiller y Szanton (1994) quienes comenzaron a utilizar el término de transnacionalidad para el análisis de los nuevos fenómenos relacionados con la migración. La

\footnotetext{
10 Elbaz, 1996: 80.

11 De ninguna manera puede sostenerse que esto suceda con todos los migrantes mexicanos, debe ser analizado por cada caso, sin embargo, por información recopilada bibliográficamente sí puedo sostener que esta situación existe en Nueva York. Ver: Smith (1992 y 2006) y Rivera-Sánchez (2004).
} 
particularidad de esta migración serian los siguientes: la masividad, contactos permanentes, simultaneidad y multilocalización.

El primero se refiere a la cantidad de personas que participan del fenómeno migratorio. En cuanto a los contactos, significa que hay una conexión sostenida en el tiempo tanto con la comunidad de origen como con otros destinos de los migrantes. La simultaneidad se refiere a que, dado el desarrollo tanto de la tecnología como de la red misma, las cosas que sucedan en cualquiera de las localidades donde tenga presencia el circuito, afectarán casi de inmediato a estos espacios. Mientras que la multilocalización se refiere a la posibilidad de que haya más de un espacio territorial en el que el circuito exista, sin embargo basta con la existencia de dos espacios: origen y destino.

La teoría de la transnacionalidad surgió como una herramienta analítica para entender la migración contemporánea. Entiéndase que no todo tipo de migración, ni únicamente a la contemporánea. Esta teoría puede aplicarse siempre que se cumplan, mínimamente las siguientes condiciones:

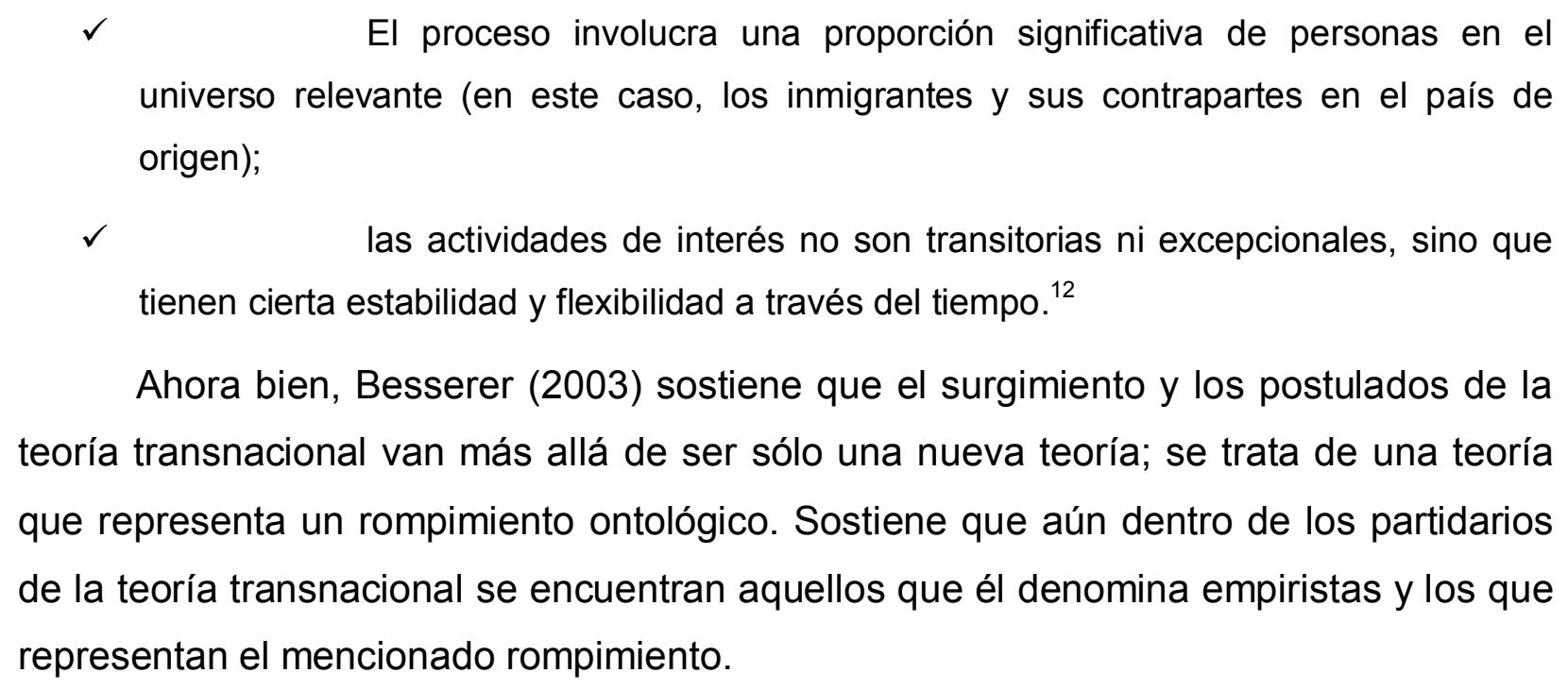
universo relevante (en este caso, los inmigrantes y sus contrapartes en el país de origen);

las actividades de interés no son transitorias ni excepcionales, sino que tienen cierta estabilidad y flexibilidad a través del tiempo. ${ }^{12}$

Ahora bien, Besserer (2003) sostiene que el surgimiento y los postulados de la teoría transnacional van más allá de ser sólo una nueva teoría; se trata de una teoría que representa un rompimiento ontológico. Sostiene que aún dentro de los partidarios de la teoría transnacional se encuentran aquellos que él denomina empiristas y los que representan el mencionado rompimiento.

La postura de empirismo transnacional amplia el objeto de estudio al considerar como sujetos a objetos y símbolos. Esto en una realidad que cruza lo local, lo regional y lo nacional. La crítica que hace Besserer a esta postura es que no critican los tradicionales métodos de investigación ni a la teoría que sostiene estos supuestos. Esto

12 Portes, 2004: 17. 
significa que no hay una reflexión en torno a la relación del sujeto de investigación con el investigador, ${ }^{13}$ a la necesidad de completar tales estudios con los métodos de otras ciencias, tanto sociales como naturales. ${ }^{14}$ Además de la falta de interés en cuestionar los postulados epistemológicos.

Por su parte los que incorporan la reflexión antes postulada se caracterizan porque establecen líneas muy claras por las que se puede distinguir el bagaje teórico y personal que está en juego a la hora de acercarse al objeto de estudio. ${ }^{15}$ Por medio de lo anterior se busca establecer lo limitado de un estudio que considere sólo el punto de vista de un autor pretendidamente objetivo y la necesidad de la transdisciplinareidad. Por ello son imprescindibles para estos estudios tanto la reflexión del narrador, como la del punto de vista. ${ }^{16}$

\section{¿Comunidades transnacionales?}

También podemos distinguir estos aportes dependiendo del actor al que se le pone énfasis. Existen aquellos que acentúan a los individuos y aquellos que se centran en el grupo social (comunidad):

(lo transnacional son) procesos mediante los cuales los migrantes fraguan y sostienen relaciones sociales multifilamentadas que relacionan a sus sociedades de origen y establecimiento. ${ }^{17}$

(lo transnacional se refiere a) el individuo y las conexiones a nivel de hogar que se forman a través de la frontera refuerzan. ${ }^{18}$

13 Lo anterior influido por los postulados de los estudios subalternos, los estudios culturales y los estudios poscoloniales. Ver la discusión propuesta por Besserer (2003).

14 En su disertación doctoral este autor emplea métodos geográficos (topografías) y retoma postulados de física cuántica.

15 Se encuentra implícito que hay un desdén por la cientificidad de estos estudios, que en una disyuntiva entre un deseo de buscar la verdad y la reflexión epistémica de la ciencia como una suposición de afirmaciones lógicas posibles, se prefiere la segunda.

16 Esto se refiere al reconocimiento de la posición de clase y etnia, además de historia personal de la que parte el autor a la hora tanto de definir el objeto que será su estudio, pero también al establecer su marco teórico de referencia (ya sea que lo haga concientemente o no)

17 Basch, Glick-Schiller y Blanc, 1994: 270. 
Esto lleva a una de las discusiones más importantes que se han desatado en el campo de los estudios transnacionales, la definición de Comunidad. ${ }^{19}$ Es común que en los estudios sobre este tema se asuma o se identifique la existencia de un conjunto de individuos que están reproduciendo un conjunto de creencias, valores, prácticas e instituciones. El hecho de que los elementos anteriores se haga en ambos lados de la frontera y en uno o varios puntos geográficos separados ha llevado a insistir en que son comunidades transnacionales multilocalizadas. La postura frente a esta tendencia es, sin negar que efectivamente puedan existir dichas comunidades, cuestionar que sea esa la única forma que pueda, o de hecho esté adoptando, el total o la mayoría de los desplazamientos de mexicanos hacia Estados Unidos. Se prefiere la sugerencia de Pries (2006) de mesurar y catalogar las posibilidades que se puedan adoptar y se prefiere la noción de Espacio Societal Transnacional (EST).

Con esta definición se busca crear una categoría descriptiva de una más de las posibilidades de socialización humana. Esta se encuentra compuesta de cuatro tipos de espacios: lo político, lo social, lo económico y lo cultural. El que dichos espacios se encuentren extendidos a través de las fronteras obliga a distinguir entre tres formas que puede adoptar el espacio societal transnacional. Estas formas son: las relaciones, el campo y las redes $\mathrm{y}$, por último, las comunidades. Cual sea la forma que adopten dependerá del grado de transnacionalización de los cuatro primeros tipos de espacios.

La crítica común hecha a esta distinción es que sólo sirve para estudiar instituciones y no para entender relaciones de individuos. Considero que tal crítica es cierta, pero que para la investigación que pretendo realizar este esquema funciona dado que estoy interesado en migrantes en asociaciones, que es una institución migratoria. Además creo que el sólo dilucidar si en el caso de los mexicanos viviendo en Nueva York son o no comunidad transnacional se llevaría buena parte del proyecto. Asumo entonces que puede ser o no una comunidad transnacional, pero que mi interés está concentrado en las instituciones creadas a partir de la migración.

18 Levitt, 2000: 203.

19 En lo siguiente retomo el punto de vista de Ludger Pries (2000) pero expuesta con mayor amplitu y claridad más claramente en una conferencia impartida en 2006. 


\section{Redes sociales}

La teoría de la transnacionalidad se basa en la importancia que tienen las redes sociales en un grupo migrante, por medio de las cuales reconfiguran/adquieren (según el autor de que se trate) su identidad, creando con ello referencias identitarias multilocalizadas, por ello agrego algunos elementos que definen y caracterizan a las mismas.

Una red social es un campo de relaciones entre individuos y puede ser definida a través de una variable predeterminada y referirse a cualquier aspecto de una relación. Una red no es un grupo bien definido y limitado, sino una abstracción científica que se usa para facilitar la descripción de un conjunto de relaciones complejas en un espacio social dado. A su vez, cada persona es el centro de una red de solidaridad y, a la vez, es parte de otras redes. La solidaridad implica un sistema de intercambio de bienes, servicios e información que ocurren dentro de la sociabilidad. Este intercambio puede ser horizontal-en el que el canje se da entre iguales a través de un sistema de reciprocidad-, o bien puede ser vertical, cuando se da una asimetría de recursos. ${ }^{20}$

En el caso de los grupos migrantes, estas redes están compuestas por: los trabajadores que migran, un grupo de empresarios transnacionales cuya finalidad es proveer de los servicios que los migrantes necesitan, la familia que permanece en la sociedad de origen quienes necesitan del dinero de los migrantes para adquirir productos electrónicos y electrodomésticos (deseo alentado por corporaciones multinacionales, quizá las mismas para las que el emigrante trabaja). Toda esta red se ve alentada por los avances tecnológicos en el transporte a larga distancia y las comunicaciones. (Cf. Portes 2004)

Estas redes surgen como una de las estrategias para superar la exclusión y lograr una mejor adaptación, si bien no necesariamente a la sociedad mayor de manera individual, pero sí de manera colectiva. También surgen como respuesta a una sociedad muy hostil hacia grupos raciales determinados. Este podría ser el caso de algunos migrantes mexicanos, si consideramos que la migración transnacional ha creado redes muy fuertes con repercusiones hacia ambos lados de la frontera, pero primordialmente hacia México. Al mismo tiempo se ha documentado poco avance en la

20 Lomnitz, 2001: 181. 
integración a la sociedad norteamericana, lo cual se ha adjudicado, precisamente a lo sólido de las redes que no obligan a la búsqueda de mejoras en las condiciones de vida por medio de una mayor integración. ${ }^{21}$

Un elemento importante en la constitución de las redes sociales es el de la identidad. A través de las redes sociales se da consistencia a comunidades imaginadas que crean un sentido a las identidades, la característica de dichas identidades es que:

construyen comunidades dentro de un contexto de desplazamiento territorial, lugares relocalizados, y al final construyen identidades translocales tanto como identidades migrantes, como producto de la conexión entre las identificaciones locales y globales que son construidas en los constantes ires y venires del circuito migratorio. ${ }^{22}$

Ahora bien, las dichas identidades tienen como referencia, ya no el territorio de destino, ni aún el de origen, más bien son identidades multilocalizadas, por lo que su lealtad es hacía la red en sí misma; hacía el circuito migratorio. Esto porque la identidad que están construyendo reconfigura el lugar de origen al mismo tiempo que da significado al lugar de llegada; crea una nueva identidad. Por supuesto que es un proceso complejo, no es una causalidad directa y, sostengo, que no en todo el fenómeno migratorio México-Estados Unidos podemos hablar de migración transnacional; ${ }^{23}$ por lo tanto de identidades del tipo que aquí estoy hablando.

Se ha visto y es una hipótesis de este trabajo, dadas las condiciones antes señaladas en las que viven los migrantes mexicanos, que conforme las redes se desarrollan aumentan su interacción con la sociedad receptora, esto reformulando su identidad y prácticas, pero no necesariamente volviéndose como ésta. No hay procesos de aculturación o asimilación, sino que se crea algo nuevo, pero que está íntimamente ligado a la red migratoria multilocalizada. Esto es importante porque permite al estudio considerar las actividades de los grupos de migrantes tratándolos como miembros de

21 Ejemplos de redes fuertes y poca integración (mejoras en las condiciones de vida) son Smith (1992 y 2006) y Faist (1995).

22 Rivera-Sánchez, 2004: 237.

23 Un buen principio, si bien inicial, para mesurar la existencia de estos circuitos es el propuesto por Pries (2000), quien sostiene que sólo la existencia de los elementos siguientes puede hablar de la existencia de lo que él llama espacios sociales transnacionales, estos son: prácticas, instituciones, artefactos y un sistema simbólico. 
un grupo asible que lucha por reconocimiento en la sociedad, pero considerando su particularidad. En Nueva York, tanto por el contexto, como por el desarrollo de la propia red, espero encontrar muchos elementos que permitan un análisis sustancioso.

Después del recorrido hecho podemos sostener que la importancia de lo étnico es resultado de la necesidad de robustecer la idea de Estado-nación, que la manera en que hasta hace poco se había considerado la existencia de grupos de migrantes era por medio de ideas asimiliacionistas, el pluralismo étnico; la aculturación. Sin embargo, y como lo hemos visto atrás, las condiciones han cambiado, fenómenos como la migración y la teoría transnacional trata de dar respuesta a estas.

\section{Ciudadanía transnacional}

La cuestión de los migrantes dentro del contexto hasta aquí planteado es sumamente adverso. En cuanto a la adquisición de la ciudadanía Gellner señala que:

En esta esfera de historia racional, evidentemente, hay ciudadanos de segunda clase, compañeros de viaje, provistos en el mejor de los casos de una visa de inmigrantes o de permiso de ingreso en la plena racionalidad, hombres vivamente ansiosos que esperan a ver si se les otorga la plena ciudadanía. Si la adquieren estos se debe a la cortesía de sus superiores que generosamente los incorporan en su trayectoria más feliz. ${ }^{24}$

Esto significa que la adquisición de la ciudadanía ha estado atravesada por la diferencia y la desigualdad. Básicamente se ha tratado como un problema de adquisición de derechos que se relaciona directamente con el reconocimiento como otro. Este problema se acentúa con la irrupción del fenómeno migratorio.

Son diversas las posturas que, dentro de las investigaciones sobre migrantes y relacionadas con la teoría transnacional, buscan definir la misma y de las que a continuación sólo presento algunas. Después intento encontrar puntos en conjunción con los cuales obtener una primera definición para empezar a pensar en la investigación de campo.

24 Gellner, 1989: 60. 
Ciudadanía Social: trabajo y segunda generación.

La ciudadanía social significa participación en la vida económica y social, la cual es facilitada por la calidad en la escuela y trabajo. La ciudadanía social también forma una base para el involucramiento en la política. Entre otras formas de privaciones, tales como altas tasas del crimen y falta de redes sociales sostenibles, la formación de subclase es la exclusión a largo plazo de ciertos grupos de la ciudadanía social. ${ }^{25}$

Este concepto lo retoma Faist (1995) para aplicarlo a su investigación sobre mexicanos de segunda generación en Estados Unidos y turcos, también de segunda generación, en Alemania. La intención de su trabajo es explicar la baja inserción de jóvenes egresados de escuelas de educación media superior al mercado laboral, así como también el mantenimiento de condiciones de vida muy bajas. Lo anterior contradice a los supuestos de otras migraciones en las cuales a partir de la segunda generación había un incremento en las mejoras de las condiciones de vida. Este autor sostiene que la ciudadanía social refiere a la acción del Estado para procurar condiciones de vida aceptables para su población. En este caso establece que, si bien en Estados Unidos no se considera ciudadanos de primera a los nacidos en su territorio, sí tienen ciertos derechos y Estado cierta obligación hacia ellos, son denominados habitantes (denizens).

El concepto de ciudadanía social refiere a las obligaciones del Estado Benefactor, éstas pueden estar delineadas por raza, etnicidad o clase e implica a las directrices que orientan los programas del mismo. Se argumenta que:

A fin de hacer que el concepto de ciudadanía sea útil para análisis empíricos, necesitamos ampliar la perspectiva de Marshall, especialmente en lo concerniente al estatus legal y étnico de los miembros de un régimen democrático. Primero, Marshall enfatiza la clase; sin embargo, el desarrollo de los Estados de bienestar occidentales también ha sido dirigidos por clivajes étnicos y de inmigrantes. Segundo, los derechos sociales no han sido garantizados exclusivamente para los ciudadanos, sino también para los miembros residentes que son ciudadanos extranjeros. ${ }^{26}$

25 Faist, 1995: 140.

26 Ibid, : 17. 
Debo agregar que la definición de Marshall de ciudadanía es "un estatus otorgado a aquellos que son miembros completos de una comunidad. Todos aquellos que poseén el estatus son iguales con respecto a los derechos y deberes con los cuales el estatus es dotado". ${ }^{27}$ Una diferencia importante entre estas dos posiciones es que, mientras que Marshall basa su definición en derechos (de los ciudadanos), Faist en obligaciones (del estado para los ciudadanos), además de reconocimiento y el tener la oportunidad de participar, por ejemplo en los mercados laborales. Esto incluso para aquellos que no tienen un estatus legal reconocido; que no son ciudadanos, que son inmigrantes. "estos derechos no están directamente ligados al estatus legal, pero están implícitos en el nivel de subsistencia que es requerido para un estándar decente de vida". 28

Una crítica que puede hacerse a este tipo de estudios es que, si bien, en general es positivo que se reflexione y trate sobre lo que sucede en el país de destino; me parece que es necesario incluir otro tipo de fenómenos que suceden al mismo tiempo y que tienen como principal fuente el país de origen. Tal es el caso de los intercambios de bienes, la circularidad de los flujos migratorios, el papel de las redes sociales, las inversiones en proyectos de desarrollo en lugares de origen, entre otras.

Los resultados son que la etnia, raza y clase son determinantes en la lucha por la incorporación de los ciudadanos al sistema de vida norteamericano. Sin embargo no hay un tratamiento sobre los efectos de las denominadas prácticas transnacionales.

Ciudadanía Flexible: porque también los empresarios migran.

Un trabajo distinto en cuanto a planteamientos, objeto de estudio y propuesta teórica es el de Aihwa Ong (1999) quien está interesada en el fenómeno migratorio proveniente de China y sus territorios (Taiwán, Singapur, Hong Kong), especialmente de los empresarios. También está interesada en entender como se reconstruye o adapta la identidad china (que suele estar asociada a valores tradicionales) a las condiciones de la modernidad, la capitalización, la expansión económica de ese país y la importancia que el mismo ha adquirido a través de los años recientes.

27 Marshall, 1973: 84.

28 Faist, 1995: 16. 
Ella propone el concepto de ciudadanía flexible para analizar este tipo de migración y sus efectos.

"Ciudadanía Flexible" se refiere a las lógicas culturales de acumulación capitalista, viajes y el desplazamiento que induce a los sujetos a responder oportuna y fluidamente para cambiar las condiciones político-económicas. En su intento de acumular capital y prestigio social en la arena global, los sujetos enfatizan, y son regulados por, prácticas que favorecen la flexibilidad, movilidad y reposicionamiento en relación a los mercados, gobiernos y regimenes culturales. Estas lógicas y prácticas están producidos dentro de estructuras particulares de significados sobre la familia, género, nacionalidad, movilidad de clase y poder social. ${ }^{29}$

Este concepto surge en el contexto del fortalecimiento económico de China y la necesidad de sus ciudadanos de mejorar sus condiciones de vida y ampliar sus negocios, muchas de las veces multimillonarios. La estrategia que ellos están siguiendo es enviar a sus descendientes a escuelas extranjeras (principalmente en Estados Unidos, pero también en Europa), propiciar su integración (pero sin jamás olvidar sus lazos familiares). En tanto que el negocio familiar se desarrolla, la familia cada vez más vive en un contexto de hipermovilidad, de tal manera que muchos de ellos suelen regresar los fines de semana a China (o a alguno de los territorios).

En este caso el papel del Estado es primordial ya que es quien ha impulsado a sus ciudadanos a salir del país, así como los alienta a mantener sus lazos sociales. El estado reconoce una ciudadanía aunque se encuentren viviendo en otro país, mantiene sus libertades (principalmente empresariales) y acepta que puedan obtener ciudadanía en otro país.

Si bien esta autora intenta completar su definición aludiendo a algunos valores culturales, que en algún momento ella misma desestima, parece que su definición se encuentra básicamente limitada a lo flujos económicos y sus derivados. La flexibilidad y fluidez que son elementos centrales en su propuesta, aluden a un conjunto de prácticas empresariales. Esto es un tanto comprensible dado que su objeto de estudio son precisamente estos sujetos sociales que tienen la capacidad económica y a los que se les incita a la integración por medio de la educación y adiestramiento en prácticas

29 Ong, 1999: 6. 
sociales. Siendo este el caso, podemos sugerir que, si bien algunos elementos ayudan a esclarecer el panorama que se observa en la migración de mexicanos, difícilmente podemos considerar esta propuesta íntegramente para explicar nuestro objeto de estudio.

Ciudadanía dual: los pasaportes sin derechos.

Esta tiene como características el que cierto estatus sea reconocido con derechos amplios y reconocidos en el país de origen y un mínimo de derechos para inmigrantes establecidos en el lugar de destino; esto último se ha denominado denizenship. La existencia de esta posibilidad no es tan remota si observamos los intereses, actitudes y políticas de lo gobiernos hacia sus expatriados (Cf. Faist 2000), por ejemplo en la importancia de las remesas y la mano de obra barata, según sea el caso. Aunque, también puede ser una estrategia de los gobiernos para expandir sus negocios, obtener mayores divisas o situarse mejor en el mercado internacional ${ }^{30}$

Un aspecto relacionado con la ciudadanía dual es la nacionalidad dual. La diferencia es que, si la ciudadanía dual implica cierto tipo de derechos y obligaciones, la nacionalidad dual es sólo la obtención de un pasaporte:

La ciudadanía dual. Una persona obtiene pasaportes de dos Estados-Nación y tiene derechos y obligaciones completos en ambos, aunque una ciudadanía está usualmente en descanso. Sólo la ciudadanía del actual país de residencia es operativa. El segundo es la nacionalidad dual. La nacionalidad dual es diferente de la ciudadanía dual en que los derechos bajo la primera están más restringidos que bajo la segunda ${ }^{31}$.

\section{Ciudadanía transnacional y estado.}

Hay varias posturas en relación para describir la relación entre ciudadanía y Estado-nación. Una de ellas considera que la ciudadanía transnacional se encuentra en un momento en que se desvanece el Estado-nación. En esta versión, se argumenta que el surgimiento de una identidad híbrida entre los miembros de un grupo de transmigrantes "es producto del hecho de que la 'unidad' de una nación es sólo

30 Ver, por ejemplo: Ong (1999).

31 Faist, 2000: 202. 
'imaginada"”32. Parte de sus planteamientos se basan en el que las nociones de territorio han cambiado drásticamente, de tal manera que este elemento fundador del estado se ve subsumido a la existencia propia de los patrones culturales o diferenciadores étnicos. Aunque también se basan en que el tipo de actores que surgen actualmente exceden

las categorías con las que opera el Estado. Su condición "difusa" entre campesinosproletarios, y sus "identidades híbridas" anticipan un nuevo período: el del desvanecimiento histórico de la preeminencia de la imagen del Estado-nación como unidad política, cultural y social predominante (Kearney 1995). ${ }^{33}$

Es notorio que para aquellos que sostienen esta postura, el Estado-nación es una etapa que está siendo superada. Esta misma lógica está en concordancia con los planteamientos posmodernos, en este sentido, podríamos hablar de "espacios posmodernos". Una de las críticas que se puede hacer es que, si bien el poder de los Estados ha disminuido, es bastante cuestionable asegurar que son en absoluto importantes. La aseveración con la que no estoy de acuerdo es la que sostiene que el proceso de desvanecimiento del estado es progresivo y terminal; esto es que desembocará en la desaparición del mismo.

Otra manera en que se ha analizado la relación con el Estado es considerar que esta es una nueva etapa, en la que, si bien, hay cierta pérdida de capacidades del estado, ya sea a manos del capital financiero y cultural o por organismos políticos internacionales, no por eso deja de tener relevancia capital. En este caso la ciudadanía tendría como referente a los países incluidos en la migración, se obtendría una ciudadanía dual.

Una manera diferente de entender la relación de ciudadanía y Estado es considerar que la étapa actual en la que se redefinen los ámbitos de acción del Estado no implica la desaparición del mismo, sino su transformación, este es el caso del trabajo de Ong (1999), ella considera que:

\footnotetext{
32 Besserer, 1999: 6-7.

33 Citado en Besserer, 1999: 7.
} 
En contraste con los argumentos sobre el desvanecimiento del Estado, yo argumento que los estados asiáticos del posdesarrollo responden positivamente al capital global, ya sea al acoplarse transnacionalmente a agencias multilaterales y capital o experimentando con soberanía gradual como una forma de hacer sus sociedades más atractivas al capital global. ${ }^{34}$

Esta otra postura aboga por el establecimiento de una manera distinta de concebir al Estado, en el caso mencionado, ella sostiene que de la unión de la modernidad clásica del mundo occidental y la filosofía confucionista, ${ }^{35}$ se crea una modernidad distinta cuyos valores máximos son, precisamente, la diferencia que tienen con occidente. Sostiene que esta narrativa parte de una diferencia instrumental que el propio estado chino ha creado para ampliar sus redes comerciales (por medio de sus empresarios), pero que la propia sociedad la ha adoptado y que consideran estar creando un futuro moderno, pero basado en principios tradicionales chinos. ${ }^{36}$

Ciudadanía transnacional: primer esbozo.

Me parece que con los elementos hasta aquí descritos es posible avanzar en la propuesta de un concepto de ciudadanía transnacional que permita un análisis más complejo y completo en relación al tema que se propone.

El concepto de ciudadanía que emerge de la discusión arriba planteada es uno que cuestiona tanto el papel de la nación, pero también el de la comunidad. Cualquier reformulación que hagamos deberá ser considerando las condiciones actuales, pero también el cambio en los supuestos que dieron coherencia y lógica al siglo XIX; esto es

\footnotetext{
34 Ong, 1999: 230.

35 Como cualquier refuncionalización de símbolos e ideologías, el resurgimiento de valores tradicionales responde a intereses individuales, familiares y de Estado; los individuos se reconocen como chinos fuera del país (Chinese overseas) para poder hacer negocios en China, las familias para que los hijos salidos de China a estudiar regresen con ellos y sean una fuente de recursos. En cuanto al Estado, la puesta en marcha de esta ideología sirve para propiciar el desarrollo económico, la ampliación de negocios, el desarrollo de industrias, entre otras.

36 Por supuesto ella no cree en la recuperación del confusionismo, o al menos no como elemento que diferencie a occidente de China, sino que enfatiza las prácticas transnacionales, la reunificación familiar, el deseo de integrarse a la sociedad occidental, ente otros elementos para sostener que se crea una diferente manera de ser occidental y de ser Estado.
} 
la homogeneidad cultural (o al menos como su posible y deseable consecución) así como la inevitable presencia y fortaleza del Estado-Nación.

Más aún, lo que nos queda es intentar dar una explicación coherente y lógica a lo que en la realidad ya sucede; los sujetos son transnacionales, tienen prácticas que no se subordinan a las fronteras, exigen (en algunos casos) demandas muy puntuales que cuestionan la capacidad y permanencia de un estado que intenta dar respuestas, con quizá, muy poca idea de la situación a la que se enfrenta.

En la situación actual, uno de los debates más importantes y con el que debemos ser precavidos es en la exaltación de las capacidades y voluntades de los migrantes, en sus prácticas e ideologías. También se debe tener en cuenta que esta ciudadanía representa la posibilidad de mejorar las condiciones de vida; en cierta manera implica dar un uso más adecuado o menos pernicioso a las redes del que pudieran tener, esto no implica abogar por una asimilación integral, sino que se tenga la posibilidad de mejorar, pero sin los obstáculos a los que actualmente se enfrenta quien desea hacerlo.

En lugar de ser una fuerza desnacionalizadora que conspira contra la integridad de la sociedad receptora, las actividades transnacionales pueden hacer posible una adaptación exitosa a ella al proveer oportunidades de movilidad económica y neutralizar el efecto de la discriminación. Para la segunda generación, en particular, esto ofrece un valioso contrapeso frente a un implacable proceso de aculturación que lleva a que los niños, aun a temprana edad, abandonen su idioma paterno y adopten uniformemente las normas y estilos de la cultura receptora. ${ }^{37}$

Con estos primeros elementos se propone un esquema de análisis para una situación especial: los migrantes mexicanos que viven en la ciudad de Nueva York.

\section{Parte III: Ciudadanía transnacional en Nueva York.}

¿Cuáles son las dinámicas que se establecen en torno a la lucha contra la exclusión en sociedades multiétnicas altamente desarrolladas? Esta es la pregunta general que guía la investigación que sirve como ejemplo de la realización de un

37 Portes, 2004: 390. 
estudio basado en la noción de ciudadanía transnacional. La misma se compone de diversos elementos y recurre a distintos conceptos a fin de darle respuesta.

La intención y aportación de esta investigación a la teoría transnacional sería analizar las condiciones en las que la comunidad se encuentra en la sociedad a donde llegan; responder a la pregunta ¿Qué sucede con los migrantes transnacionales en la sociedad de destino?, ¿Cómo se recrean y transforman, y en qué sentido en el contexto de los Estados Unidos?

\section{Objetivo}

El objetivo es reconstruir la historia del surgimiento de las asociaciones de migrantes, pero entendiendo su historia como una reflexión y puesta en práctica de que es lo que significa y ha significado la ciudadanía. Por otra parte también se busca capturar el significado que tienen las actividades que llevan a cabo las organizaciones para la construcción de la ciudadanía de los migrantes mexicanos.

Una vez establecida la pregunta guía de la investigación es necesario particularizar y localizarla dentro del amplio contexto establecido al principio. Esto se logra al establecer los objetivos particulares y los espacios.

\section{Objetivos particulares}

Se espera contribuir a la reflexión teórica de la teoría transnacional, tal como se señaló antes, indagando sobre las condiciones en las que se encuentran las comunidades migrantes en la sociedad receptora. Esto significa observar el movimiento en una dirección opuesta a como se ha visto tradicionalmente, esto es, desde la sociedad de origen a la de destino. Esto tiene implicaciones metodológicas importantes, pero también teóricas.

Entender la dinámica que siguen las asociaciones de migrantes mexicanos como un sujeto que, al formarse, se integra a una red de relaciones con contactos tanto en la sociedad de destino como en la de origen. Es importante entender la manera de operar de estas instituciones ya que son la formalización de las redes sociales, además de que permite vislumbrar el tipo de relación que emerge entre estos sujetos sociales 
con el Estado-Nación, como se reconfiguran tales relaciones y que resultado tiene en la cuanto a la inclusión y exclusión en ambos espacios.

Las nuevas condiciones en las que la interacción social se ve atravesada por los avances tecnológicos, el achicamiento del mundo, entre otros plantea una ruptura en cómo se ha construido la idea de ciudadanía y la manera como se establece este sujeto. Esta investigación pretende, por lo tanto, proponer un esquema de análisis teniendo como sujeto de estudio a estos grupos, sin embargo, entendiendo que esta confrontación tiene otros frentes a los que también es necesario considerar. Estas consideraciones son de tipo temporal pero también de ámbitos de trabajo.

\section{Contexto del espacio de investigación.}

En el seno de la sociedad neoyorquina una serie de fenómenos se conjugan para formar un panorama que es sumamente especial, algunas de éstas son:

$+\quad$ En términos económicos, con fuertes repercusiones sociales, esta ciudad es considerada una de las tres más importantes del mundo; es considerada una ciudad global. Esto es que en ella se llevan a cabo procesos, principalmente financieros, lo que provoca que sea de las más importantes en los procesos de innovación administrativa, procesos legales, de marketing, entre otros. (cf. Sassen 1999). Esto tiene consecuencias sociales, aunque en el esquema de Sassen no sean tratados a profundidad.

+ Esta ciudad ha sido la puerta de entrada de migrantes, básicamente europeos en los dos siglos anteriores, pero en las últimas décadas ha adquirido mayor relevancia la presencia de centroamericanos $y$, más contemporáneamente, de mexicanos.

$+\quad$ Aunado y como consecuencia de lo anterior, en esta ciudad se tiene una más avanzada legislación en torno a la coexistencia de personas de diferentes orígenes. De la misma manera, la existencia de grupos minoritarios como los migrantes mexicanos son un tanto más tolerados que en otras partes de Estados Unidos.

$+\quad$ Existe un conjunto de asociaciones que tienen como objetivo (entre otros) el pleno desarrollo de los migrantes y la obtención de un reconocimiento como 
ciudadanos de facto. Más adelante puntualizo estas ideas. Tales asociaciones son, por ejemplo: La asociación Tepeyac ${ }^{38}$, el sindicato UNITE ${ }^{39}$, entre otros.

$+\quad$ La presencia de mexicanos se ha incrementado considerablemente y las redes sociales que conforman los circuitos se encuentran sumamente desarrolladas. ${ }^{40}$ Tal desarrollo puede observarse desde los procesos de obtención de espacios, la victoria en luchas laborales y la existencia de las asociaciones antes mencionadas con un alto grado de participación de mexicanos, ilegales o no.

$+\quad$ Se observa y se ha documentado una inmensa gama de prácticas transnacionales, han surgido en algunos casos instituciones transnacionales.

\section{Organizaciones de migrantes}

Se plantea que el análisis de las asociaciones de migrantes se realice considerando, al menos los siguientes tres aspectos, los cuales son, a saber, el tiempo; la diferencia entre lo interno/externo; y la dimensión de publico/privado.

El desarrollo de las asociaciones de migrantes ${ }^{41}$ está marcado por un momento particular en el cual la dinámica, tamaño y capacidad de acción de las mismas cambió radicalmente. Como ejemplo cito el desarrollo de la Asociación Tepeyac ${ }^{42}$ esta organización es resultado de la unión de diferentes organizaciones y asociaciones, la creación de ésta data de 1997 (aunque haya tenido una largo desarrollo previo) y participa en actividades diversas como la defensa de derechos humanos y laborales, asesoría legal, enseñanza de inglés, organización de eventos religiosos, entre otros.

Dicha organización tuvo un papel importante en el movimiento nacional por la regulación de los inmigrantes en Estados Unidos (aunque carecía de un fuerte respaldo

\footnotetext{
38 Rivera-Sánchez, 2004.

39 Malkin. S/F

40 Cf. Herrera (2005), Smith (1992), Rivera-Sánchez (2002 y 2004).

${ }^{41}$ Los aspectos señalados en relación a las organizaciones de migrantes en Nueva York proviene de una plática con Liliana Rivera-Sánchez, excepto cuando se señale lo contrario.

42 Ver: Rivera-Sánchez, 2004.
} 
económico). Sin embargo, después de los atentados del 11 de septiembre a las torres gemelas del World Trade Center situadas en Nueva York, este movimiento (así como las propuestas y posibilidades de que se logrará la reforma legal) se ve sepultado bajo los escombros de las torres... El endurecimiento de las políticas de asimilación, la militarización de la frontera, la paranoia al extranjero son resultados de la guerra contra el terrorismo. La Asociación Tepeyac responde con programas de apoyo psicológico a familiares de las víctimas, lo cual redunda en la obtención de recursos provenientes de ONG's internacionales.

Como se intenta señalar, el ataque terrorista del 11 de septiembre marca el desarrollo de la Asociación Tepeyac, tanto al frenar sus actividades políticas como al proveer de recursos para profesionalizar a su estructura de personal. De esta manera, se reconoce que la dimensión temporal esté marcada por un antes y un después en relación a esta fecha. Para los fines de esta investigación se pretende recuperar la historia del desarrollo de las asociaciones antes y después del punto de inflexión señalado, pero siempre retomando como hilo conductor la construcción del ciudadano que se hace dependiendo de las condiciones contingentes particulares.

Un aspecto relacionado a este punto es la diferencia entre lo interno/externo. Por esta diferencia me refiero a la separación metodológica que haré entre lo que sucede dentro de la asociación y lo que ésta misma hace con sus afiliados, beneficiarios, público o miembros. La historia del desarrollo de las asociaciones es sumamente interesante y reconozco que puede determinar la relación que se establece con la población a la que está dirigida, sin embargo, este trabajo estará enfocado a las actividades de las asociaciones hacia el exterior. Esto no niega la cuestión interna antes mencionada y se recuperará en tanto que influya en la caracterización del sujeto pleno con derechos al que con dichas prácticas se aluda.

Un último elemento es la dimensión público/privado. Con esta intento marcar una primera categorización de las asociaciones de migrantes y se refiere al tipo de actividades a las que se dediquen las mismas. Por asociaciones de migrantes de tipo público me refiero a aquellas cuyas actividades estén encaminadas a tratar aspectos 
relacionados con la vida pública ${ }^{43}$ (o sea no confinada al ámbito personal) de los migrantes, tales como derechos humanos, políticos, laborales. Dado que la ciudadanía puede ser entendida como la relación de los ciudadanos en miras de la igualdad a pesar de las diferencias personales, las cuales caerían dentro de lo privado. Esta división suele ser muy confusa y en constante cambio y yuxtaposición. Un primer elemento que pudiera marcar la diferencia es que lo privado deja de serlo cuando entra en discusión o diálogo con otras diferencias privadas o a la discusión pública. Por ello, en este trabajo, las asociaciones de interés serían las relacionadas con lo público, y con lo privado sólo en cuanto fueran parte de una discusión pública.

\section{Plan de investigación}

Esta investigación estará dividida en dos partes, la primera de ellas es la etapa que correspondería al nivel de maestría y una segunda al nivel de doctorado.

En la primera etapa se planea trabajar en la reconstrucción de la historia del desarrollo de la Asociación Tepeyac y en la de algunas asociaciones de fútbol en la ciudad de Nueva York. Lo anterior porque el tiempo en el que se requiere que se haga la investigación es muy corto.

Por otro lado, en la segunda etapa se plantea ampliar los objetos de estudio a otras organizaciones sobre las que ya se sabe de su existencia, como son la Casa Puebla (representación del gobierno de Puebla en Nueva York), la representación en la ciudad del Partido de la Revolución Democrática, Mixteca Inc. (asociación de migrantes mixtecos primordialmente médicos) y se deja abierta la posibilidad de trabajar con asociaciones en contra de los migrantes, esto también en la búsqueda de rescatar la disputa por la ciudadanía.

\footnotetext{
${ }^{43}$ La definición de lo público puede estar relacionada con las nociones de política y gobierno (conjunto de mecanismos para tratar con los problemas colectivos); o bien estar referido al mantenimiento del orden en la relación del gobierno con los ciudadanos; o bien, a la diferencia de las consecuencias de los actos, las cuales pueden ser limitadas (lo privado) y las extendidas (lo publico). Cf. Escalante, 1993.
} 


\section{Bibliografía.}

Basch Linda, Glick Schiller Nina y Szanton Blanc Cristina (1994): Nations Unbound. Transnational Projects, Postcolonial Predicaments, and Deterritorialized Nation-States. Grondon and Breach Publishers. 267- 292 pp.

Besserer, Federico (1999): "Estudios transnacionales y ciudadanía transnacional" en Gail Mumert (editor) Fronteras fragmentadas. Michoacán, Colmich-Cidem. 215-238 pp.

Besserer, Federico (2003). Contesting Community. Dissertation. Stanford University. 303 pp.

Elbaz, Mikhaël y Denise Helly (1996): "Modernidad y postmodernidad de las identidades nacionales" en Revista Internacional de Filosofía Política. No. 7. Barcelona, UNEA-UAM.

Escalante Gonzalbo, Fernando (1993): Ciudadanos imaginarios. Memorial de los afanes y desventuras de la virtud y apología del vicio triunfante en la República Mexicana. Tratado de moral pública. México, El Colegio de México. 308 pp.

Faist, Thomas (1995): Social Citizenship for Whom?: Young Turks in Germany and Mexican Americans in the United States. Gran Bretaña, Antony Rowe. 243 pp.

Faist, Thomas (2000): "Transnationalization in international migration: implications for the study of citizenship and culture" en Ethnic and Racial Studies. Vol 23, No. 2. Taylor and Francis. 189-222 pp.

Gellner, Ernest (1989): Cultura, Identidad y Política. Barcelona, Gedisa. 202 pp. 
Glick Schiller, Nina y Georges Eugene Fouron (2001): Georges Woke up Laughing. Long-distance nationalism And the Search for Home. Duke University Press, 325 pp.

Guarnizo, Luis Eduardo y Smith Michael Peter (1998): Transnationalism from Below. New Brunswick, Transaction Publishers. 316 pp.

Harvey, David (1999): La condición de la posmodernidad: Investigación sobre los orígenes del cambio cultural. Barcelona, Amorrortu.

Herrera Lima, Fernando (2005): Vidas Itinerantes. México, UAM.

Jameson, Frederic (1995): El posmodernismo o la lógica cultural del capitalismo avanzado. Barcelona, Paidós. 121 pp.

Kearney, Michael (1995): The local and the global: The Anthropology of globalization and transnationalism. Annual Reviews Anthropologist.

Kearney, Michael (1995): "The Effects of transnational Culture, Economy and Migration of Mixtec Identity in Oaxacalifornia", Michael Peter Smith et al. (eds.). The Bubbling Cauldron, Race, Ethnicity and the Urban Crisis, Minneapolis: University of Minnesota Press, pp. 226-243.

Kymlicka, Will (2002): Ciudadanía Multicultural. Barcelona, Paidós.

Levitt, Peggy (2000): The Transnational Villagers. University of California Press. EU. $281 \mathrm{pp}$.

Lomnitz, Larissa (2001): "Redes sociales y estructura urbana en América Latina", en Miguel León Portilla Motivos de la antropología americanista, indagaciones en la diferencia. México, FCE. 167-197 pp.

Malkin, Victoria (s/f): "The New York Greengrocer campaign: immigrant organizing in ethnic niches". 43-53 pp. Referencia obtenida en internet. 
Marshall, T. H. (1973): Cutuzenship and Social Class. Nueva York, Cambridge University Press.

Ong, Aihwa (1999): Flexible Citizenship. The cultural logics of transnationality. Durham y Londres, Duke University Press. 322 pp.

Portes, Alejandro, Luis Guarnizo y Patricia Landolt (2004): La globalización desde abajo: transnacionalismo y desarrollo. La experiencia de Estados Unidos y Latinoamérica. México, Miguel Ángel Porrúa-Flacso.

Pries, Ludger (2000): "Teoría sociológica del mercado de trabajo" En De la Garza, Enrique (coordinador) Tratado Latinoamericano de Sociología. México, Colmex, FLACSO-México, UAM, FCE. 511-539 pp.

Pries, Ludger (2006): La situación de la migración en Europa. Conferencia presentada el 12 y 13 de junio en la UAM Iztapalapa.

Reale, Giovanni y Darno Antisemi (1995): Historia Del conocimiento filosófico y cientifico. Header.

Requejo Coll, Ferran (1996): "Pluralismo, democracia y federalismo. Una revisión de la ciudadanía democrática en estados plurinacionales", en Revista Internacional de filosofía política. Barcelona, UNEA-UAM. 92-120 $\mathrm{pp}$

Rivera-Sánchez, Liliana (2002): Searching Expressions of Identity: Belonging and Spaces- Mexican Immigrants in New York. Santa Cruz, CA, UCSC Inn and Conference Center

Rivera-Sánchez, Liliana (2004): Belongings and Identities. Migrants between The Mixteca and New York. Disertación Doctoral para obtener el grado, presentada en la Faculty of political and Social Science of New School University. 302 pp. 
Sassen, Saskia (1999): La ciudad global. Nueva York, Londres, Tokio. Buenos Aires, Eudeba.

Smith, Robert C. (1992): 'Los Ausentes siempre presentes': The imagining, making and politics of a transnational community between New York City and Ticuani, Puebla Conferencia en el Institute for Latin America and Iberian Studies, Columbia University. 48 pp.

Smith, Robert C. (2006): México en Nueva York. Vidas transnacionales de los migrantes mexicanos entre Puebla y Nueva York. México, Cámara de Diputados-UAZ-MAP. 410 pp.

Stuart, Mill (1840): Sobre la libertad. Gernika, México. 182 pag.

Stuart, Mill (1840): Sobre la libertad. México, Gernika. 182 pag.

Vertovec, Steven (2006): Políticas multiculturales y formas de ciudadanía en las ciudades europeas. Internet, accesado en marzo 15, 2006. 